ORIGINAL ARTICLE

\title{
A population based study of the impact of corticosteroid therapy and delayed diagnosis on the outcome of childhood pneumococcal meningitis
}

\author{
P B Mclntyre, C R Maclntyre, R Gilmour, H Wang
}

Arch Dis Child 2005;90:391-396. doi: 10.1136/adc.2003.037523

See end of article for authors' affiliations

\section{Correspondence to:}

Dr C R Maclntyre, National

Centre for Immunisation

Research and Surveillance

of Vaccine Preventable

Diseases, The Children's

Hospital at Westmead and

University of Sydney,

NSW, Australia, 2145;

RainaM@chw.edu.au

Accepted

11 February 2004
Background: Despite an extensive literature, the impact of both adjunctive steroid therapy and delayed diagnosis on the outcome of childhood pneumococcal meningitis is controversial.

Aim: To determine the independent contribution of corticosteroid therapy and delayed diagnosis on the outcome of childhood pneumococcal meningitis in a representative population with good access to medical services.

Methods: Data were obtained from laboratories and hospital records to assemble a population register in Sydney, Australia, 1994-99. Follow up questionnaires were completed by attending physicians.

Results: A total of 122 cases of pneumococcal meningitis aged $0-14$ years were identified. Almost $50 \%$ of 120 children with available records either died $(n=15)$ or had permanent neurological impairment $(n=39)$. Early use (before or with parenteral antibiotics) of corticosteroids protected against death or severe morbidity (adjusted OR $0.21,95 \% \mathrm{Cl} 0.05$ to 0.77 ). Delayed diagnosis was associated with increased morbidity in survivors (OR $3.4,95 \% \mathrm{Cl} 1.03$ to 11.4 ) but not with increased mortality.

Conclusion: In a population with good access to health care and after adjusting for other known prognostic variables, early recognition of pneumococcal meningitis and treatment with adjunctive dexamethasone significantly improves outcomes. These data add to those from randomised controlled trials. Implementation requires development of protocols and guidelines for use in emergency departments. n Australia and the USA, where vaccination against Haemophilus influenzae type $b$ (Hib) is widespread, Streptococcus pneumoniae is the most common cause of bacterial meningitis of children. ${ }^{12}$ Pneumococcal meningitis causes greater morbidity and mortality than most other types of bacterial meningitis, with case fatality rates as high as $20 \%$, compared to $3-13 \%$ for meningococcal meningitis. ${ }^{134}$

The importance of both diagnostic delay and adjuvant corticosteroid therapy in the prognosis of childhood pneumococcal meningitis has been controversial. ${ }^{5}$ Delayed diagnosis is difficult to define, especially outside the hospital setting. Studies have not shown a consistent association between delayed diagnosis and outcome of bacterial meningitis. ${ }^{36}$ Similarly, there are substantial practical obstacles to delivering corticosteroid therapy in the emergency management of possible bacterial meningitis, especially if it must be given before parenteral antibiotics are commenced. ${ }^{7}$ We have previously shown that prognosis is worse where lumbar puncture (LP) is thought contraindicated. ${ }^{8}$ The present study extends these observations by evaluating two additional factors, delayed diagnosis and adjuvant corticosteroid therapy, for their independent impact on the outcome of pneumococcal meningitis in a representative childhood population.

\section{METHODS \\ Case definition}

Pneumococcal meningitis was defined as isolation of Streptococcus pneumoniae from cerebrospinal fluid (CSF) or from blood from a patient with a CSF white cell count $>10$ cells $/ \mathrm{mm}^{3}$. If a lumbar puncture was not performed, meningitis was defined as isolation of Streptococcus pneumoniae from blood culture with one or more of the following:
- Clinical symptoms and signs of meningitis (headache, drowsiness, neck stiffness, photophobia)

- Meningeal contrast enhancement on CT scan

- Postmortem evidence of meningitis.

Eligible cases were aged less than 15 years, had a date of isolation of Streptococcus pneumoniae from January 1994 to 31 December 1999, and resided in the greater urban regions of Sydney, Newcastle, and Wollongong, New South Wales (NSW), Australia.

\section{Case ascertainment}

A population register was established with case finding through laboratories in the study area. Active laboratory surveillance was enhanced by cross-referencing with cases in the NSW Hospital Morbidity Database with an ICD-9-CM coded $^{9}$ discharge diagnosis of pneumococcal meningitis (320.1), all meningitis unspecified (320.0), or pneumococcal septicaemia (790.7). Clinical, demographic, and treatment details were obtained from review of the hospital records by a single observer (RG) using a standard protocol, ${ }^{8}$ with particular reference to the timing of first presentation and of antibiotic and corticosteroid use. Data from this enhanced surveillance system have been described previously. ${ }^{10}$

Risk factors for pneumococcal infection were defined according to the Australian Immunisation Handbook ${ }^{11}$ as immunosuppression (due to disease or iatrogenic), asplenia, CSF leak, or chronic diseases (such as diabetes, chronic cardiac, renal, or pulmonary disease).

\section{Outcomes of meningitis}

Outcome data were ascertained from hospital records (including outpatient attendance) and by a survey administered to 
Table 1 Univariate analysis of risk factors

\begin{tabular}{|c|c|c|c|c|c|c|c|}
\hline Risk factor & $\mathbf{n}$ & Deaths & OR $(95 \% \mathrm{Cl})$ & $\begin{array}{l}\text { Severe } \\
\text { morbidity or } \\
\text { mortality }\end{array}$ & OR $(95 \% \mathrm{Cl})$ & $\begin{array}{l}\text { Any morbidity } \\
\text { or mortality }\end{array}$ & OR $(95 \% \mathrm{Cl})$ \\
\hline $\begin{array}{l}\text { Female } \\
\text { Male }\end{array}$ & $\begin{array}{l}47 \\
73\end{array}$ & $\begin{array}{l}8 \\
7\end{array}$ & $\begin{array}{l}1.9 \\
(0.59 \text { to } 6.7)\end{array}$ & $\begin{array}{l}17 \\
21\end{array}$ & $\begin{array}{l}1.4 \\
(0.59 \text { to } 3.3)\end{array}$ & $\begin{array}{l}27 \\
27\end{array}$ & $\begin{array}{l}2.3 \\
\text { (1.01 to } 5.3)\end{array}$ \\
\hline $\begin{array}{l}\text { Delayed hospitalisation } \\
\text { Hospitalisation not delayed }\end{array}$ & $\begin{array}{l}34 \\
86\end{array}$ & $\begin{array}{r}5 \\
10\end{array}$ & $\begin{array}{l}1.31 \\
(0.35 \text { to } 4.7)\end{array}$ & $\begin{array}{l}12 \\
26\end{array}$ & $\begin{array}{l}1.26 \\
(0.50 \text { to } 3.1)\end{array}$ & $\begin{array}{l}17 \\
37\end{array}$ & $\begin{array}{l}1.32 \\
(0.55 \text { to } 3.2)\end{array}$ \\
\hline $\begin{array}{l}\text { Medical risk factor for pneumococcal } \\
\text { disease }^{*} \\
\text { No medical risk factor }\end{array}$ & $\begin{array}{r}20 \\
100\end{array}$ & $\begin{array}{r}3 \\
12\end{array}$ & $\begin{array}{l}1.3(0.25 \text { to } 5.8) \\
p=0.7\end{array}$ & $\begin{array}{r}6 \\
32\end{array}$ & $\begin{array}{l}0.91(0.28 \text { to } 2.9) \\
p=0.9\end{array}$ & $\begin{array}{r}9 \\
45\end{array}$ & $\begin{array}{l}1.00(0.34 \text { to } 2.9) \\
p=1.0\end{array}$ \\
\hline $\begin{array}{l}\text { First presentation to hospital } \\
\text { First presentation to GP }\end{array}$ & $\begin{array}{l}48 \\
72\end{array}$ & $\begin{array}{r}5 \\
10\end{array}$ & $\begin{array}{l}0.7 \\
(0.19 \text { to } 2.6)\end{array}$ & $\begin{array}{l}11 \\
27\end{array}$ & $\begin{array}{l}0.5 \\
(0.2 \text { to } 1.2)\end{array}$ & $\begin{array}{l}16 \\
38\end{array}$ & $\begin{array}{l}0.45 \\
(0.18 \text { to } 1.02)\end{array}$ \\
\hline $\begin{array}{l}\text { Otitis media } \\
\text { No otitis media }\end{array}$ & $\begin{array}{r}15 \\
105\end{array}$ & $\begin{array}{r}3 \\
12\end{array}$ & $\begin{array}{l}1.94 \\
(0.37 \text { to } 9.1)\end{array}$ & $\begin{array}{r}8 \\
30\end{array}$ & $\begin{array}{l}2.9 \\
(0.84 \text { to } 9.9)\end{array}$ & $\begin{array}{r}8 \\
46\end{array}$ & $\begin{array}{l}1.5 \\
(0.44 \text { to } 4.9)\end{array}$ \\
\hline $\begin{array}{l}\text { Lumbar puncture not done } \\
\text { Lumbar puncture done }\end{array}$ & $\begin{array}{r}16 \\
103\end{array}$ & $\begin{array}{l}7 \\
7\end{array}$ & $\begin{array}{l}11.1 \\
(2.6 \text { to } 50.0)\end{array}$ & $\begin{array}{l}10 \\
27\end{array}$ & $\begin{array}{l}4.8 \\
(1.4 \text { to } 16.6)\end{array}$ & $\begin{array}{l}13 \\
40\end{array}$ & $\begin{array}{l}6.7 \\
(1.6 \text { to } 33.3)\end{array}$ \\
\hline $\begin{array}{l}\text { Antibiotics prior to hospital } \\
\text { No prior antibiotics } \\
\text { IV/IM antibiotics within } 6 \text { hours of } \\
\text { admission } \\
\text { IV/IM antibiotics }>6 \text { hours }\end{array}$ & $\begin{array}{l}28 \\
92 \\
78 \\
41\end{array}$ & $\begin{array}{r}2 \\
13 \\
9\end{array}$ & $\begin{array}{l}0.47 \\
(0.07 \text { to } 2.4) \\
0.94 \\
(0.26 \text { to } 3.6)\end{array}$ & $\begin{array}{r}9 \\
29 \\
22\end{array}$ & $\begin{array}{l}1.03 \\
(0.37 \text { to } 2.8) \\
0.68 \\
(0.28 \text { to } 1.7)\end{array}$ & $\begin{array}{l}13 \\
41 \\
35 \\
18\end{array}$ & $\begin{array}{l}1.08 \\
(0.42 \text { to } 2.8) \\
1.04 \\
(0.45 \text { to } 2.4)\end{array}$ \\
\hline Intubation & 29 & 12 & $\begin{array}{l}10.6 \\
(1.2 \text { to } 244) \\
p=0.017\end{array}$ & 18 & $\begin{array}{l}4.9 \\
(1.1 \text { to } 24) \\
p=0.029\end{array}$ & 22 & $\begin{array}{l}4.0 \\
(0.92 \text { to } 18.6) \\
p=0.06\end{array}$ \\
\hline $\begin{array}{l}\text { No intubation, intensive care } \\
\text { (reference group, } \mathrm{OR}=1.00 \text { ) }\end{array}$ & 16 & 1 & & 4 & & 7 & \\
\hline No intensive care admission & 75 & 3 & $\begin{array}{l}0.63 \\
(0.07 \text { to } 5.9) \\
p=0.55\end{array}$ & 16 & $\begin{array}{l}0.81 \\
(0.2 \text { to } 3.3) \\
p=0.75\end{array}$ & 25 & $\begin{array}{l}0.64 \\
(0.19 \text { to } 2.2) \\
p=0.43\end{array}$ \\
\hline $\begin{array}{l}\text { Seizures within } 48 \text { hours } \\
\text { No seizures within } 48 \text { hours }\end{array}$ & $\begin{array}{l}26 \\
94\end{array}$ & $\begin{array}{r}10 \\
5\end{array}$ & $\begin{array}{l}11.1 \\
(2.9 \text { to } 44.5)\end{array}$ & $\begin{array}{l}15 \\
23\end{array}$ & $\begin{array}{l}4.2 \\
(1.5 \text { to } 11.7)\end{array}$ & $\begin{array}{l}18 \\
36\end{array}$ & $\begin{array}{l}3.6 \\
(1.3 \text { to } 10.3)\end{array}$ \\
\hline $\begin{array}{l}\text { Corticosteroids before or with } \\
\text { antibiotics }\end{array}$ & 31 & 2 & $\begin{array}{l}0.35 \\
(0.06 \text { to } 4.6) \\
p=0.5\end{array}$ & 4 & $\begin{array}{l}0.22 \\
(0.05 \text { to } 0.91) \\
p=0.01\end{array}$ & 7 & $\begin{array}{l}0.29 \\
(0.05 \text { to } 0.72) \\
p<0.01\end{array}$ \\
\hline & 27 & 3 & $\begin{array}{l}0.65 \\
(0.13 \text { to } 2.94)\end{array}$ & 11 & 0.25 & 16 & 1.5 \\
\hline $\begin{array}{l}\text { Corticosteroids after antibiotics } \\
\text { No corticosteroids (reference group, } \\
O R=1.00 \text { ) }\end{array}$ & 62 & 10 & $p=0.5$ & 23 & $p=0.74$ & 31 & $p=0.42$ \\
\hline $\begin{array}{l}\text { Age } \leqslant 12 \text { months } \\
\text { Age }>12 \text { months }\end{array}$ & $\begin{array}{l}56 \\
64\end{array}$ & $\begin{array}{l}6 \\
9\end{array}$ & $\begin{array}{l}0.73 \\
(0.21 \text { to } 2.5)\end{array}$ & $\begin{array}{l}18 \\
20\end{array}$ & $\begin{array}{l}1.04 \\
(0.45 \text { to } 2.4)\end{array}$ & $\begin{array}{l}26 \\
28\end{array}$ & $\begin{array}{l}1.1 \\
(0.5 \text { to } 2.5)\end{array}$ \\
\hline $\begin{array}{l}\text { Highest temp }>39^{\circ} \mathrm{C} \\
\text { Highest temp } \leqslant 39^{\circ} \mathrm{C}\end{array}$ & $\begin{array}{l}51 \\
67\end{array}$ & $\begin{array}{r}12 \\
1\end{array}$ & $\begin{array}{l}20.3 \\
(2.5 \text { to } 441)\end{array}$ & $\begin{array}{l}19 \\
17\end{array}$ & $\begin{array}{l}1.75 \\
(0.73 \text { to } 4.2)\end{array}$ & $\begin{array}{l}27 \\
25\end{array}$ & $\begin{array}{l}1.90 \\
(0.84 \text { to } 4.3)\end{array}$ \\
\hline $\begin{array}{l}\text { Highest temp in 25th centile } \\
\text { Highest temp }>25 \text { th centile }\end{array}$ & $\begin{array}{l}29 \\
89\end{array}$ & $\begin{array}{l}7 \\
6\end{array}$ & $\begin{array}{l}4.4 \\
(1.2 \text { to } 17.0)\end{array}$ & $\begin{array}{l}13 \\
23\end{array}$ & $\begin{array}{l}2.3 \\
(0.89 \text { to } 6.2)\end{array}$ & $\begin{array}{l}16 \\
36\end{array}$ & $\begin{array}{l}1.8 \\
(0.71 \text { to } 4.6)\end{array}$ \\
\hline $\begin{array}{l}\text { CSF white cell count } \leqslant 100 \dagger \\
\text { CSF white cell count }>100 \dagger\end{array}$ & $\begin{array}{l}20 \\
83\end{array}$ & $\begin{array}{l}1 \\
6\end{array}$ & $\begin{array}{l}0.68 \\
(0.03 \text { to } 6.4)\end{array}$ & $\begin{array}{r}4 \\
23\end{array}$ & $\begin{array}{l}0.65 \\
(0.16 \text { to } 2.4)\end{array}$ & $\begin{array}{r}8 \\
32\end{array}$ & $\begin{array}{l}1.06 \\
(0.35 \text { to } 3.2)\end{array}$ \\
\hline Total & 120 & 15 & & 38 & & 54 & \\
\hline
\end{tabular}

*Medical risk factors defined as known conditions which predispose to invasive pneumococcal disease, such as asplenia, CSF leak, and immunosuppression. †Denominator not equal to 120 due to missing values, as some patients did not have a CSF result available.

treating physicians. The survey questionnaire was sent to the child's paediatrician or family physician after discharge from hospital, in most cases more than six months later. RG also telephoned the doctors who did not return surveys or did not answer questions correctly. No direct contact with families was made by the doctors or study personnel. The purpose of the survey was to:

- Confirm hospital records

- Ascertain any morbidity not identified in hospital records

- Confirm the functional status of the child at the most recent encounter.
Neurological abnormalities were categorised as severe or mild to moderate morbidity from the most recent available data. Severe morbidity was defined as significant functional impairment, such as hemiparesis or quadraparesis, hydrocephalus requiring a ventricular shunt, visual loss, and all cases with marked intellectual impairment. Mild to moderate morbidity was defined as any other unequivocal neurological abnormality with lesser functional impairment. These included hearing loss, seizures, well defined gross or fine motor problems such as balance or hand-eye coordination, developmental delay, and mild to moderate intellectual impairment. The variable "any morbidity or mortality" 
included mortality and all grades of morbidity as defined above.

\section{Delayed diagnosis and hospitalisation}

Delayed hospitalisation was defined as more than one medical visit during this illness, before admission to hospital or death. This implies that the diagnosis of meningitis was not made at the first medical consultation, so the variable for delayed hospitalisation is taken as a proxy for delayed diagnosis.

\section{Corticosteroid therapy}

Corticosteroid therapy included parenteral administration of dexamethasone or other corticosteroid. Early corticosteroid therapy was defined as a recorded time of administration before or with the first dose of parenteral antibiotics.

\section{Penicillin resistance}

Penicillin sensitivity of Streptococcus pneumoniae isolates was tested by 0.5 unit penicillin disc and/or $1 \mu \mathrm{g}$ oxacillin disc. Where resistance to penicillin was suspected from these screening methods, tube dilution techniques or commercial agar dilution antibiotic gradient method (E-test, AB Biodisk, Sweden) were used to test for the minimum inhibitory concentration. $^{8}$

\section{Data analysis}

Clinical, therapeutic, and laboratory predictors of outcome were examined in univariate and multivariate analysis. In addition to delayed diagnosis, other clinical variables included age, sex, point of first medical contact (hospital or general practitioner), type of hospital (tertiary referral or other), and presence of certain clinical signs (such as seizures, high and low temperature, or recorded neurological abnormalities). In addition to corticosteroid therapy, other therapeutic variables included a history of antibiotic use prior to hospital admission and time to commencement of parenteral antibiotics after admission. Laboratory variables included low CSF white cell count $(<100$ white cells per $\left.\mathrm{mm}^{3}\right)$, low CSF glucose $(<2.5 \mathrm{mmol} / \mathrm{l})$, high CSF protein $(>1 \mathrm{~g} / \mathrm{l})$, and resistance to penicillin. Epi-Info version $6^{12}$ was used for univariate analysis, and Egret $^{13}$ for stepwise logistic regression analysis.

\section{Ethical implications}

Ethics committee clearance was obtained from the committees of all the relevant health services within the defined geographical region.

\section{RESULTS}

\section{Demographics}

A total of 122 eligible cases of pneumococcal meningitis were identified between 1994 and 1999. Two cases with no available clinical data were excluded from further analysis. The median age of cases was 13 months, with a range of
1.78-179 months. Almost half of cases (46.3\%) occurred under the age of 12 months, and $89 \%$ under the age of 5 years. The majority of cases $(74 / 120,62 \%)$ were male. Cases were treated at 21 hospitals, with 50/120 (42\%) admitted to hospitals having a tertiary referral role.

\section{Presentation}

The first presentation was to hospital in 48/120 (40\%) and to general practice (GP) in 72/120 (60\%). Of the GP group, 23/72 (32\%) had two or more presentations before admission to hospital, and $6 / 48(12 \%)$ whose first presentation was to hospital had more than one attendance. In 55/120 (46\%) cases, hospital admission occurred more than 24 hours after the time of onset of symptoms recorded in the clinical records.

\section{Laboratory and clinical features}

A lumbar puncture (LP) was performed in 103/120 (85\%), but was after initiation of parenteral antibiotics in $43 / 103$ $(42 \%)$. The CSF Gram stain showed Gram positive cocci in 90/103 (87\%). Streptococcus pneumoniae was cultured from CSF $(+/-$ blood $)$ in $79 / 103(77 \%)$ cases, and in blood only in $41 / 120(33 \%)$ cases. Where sensitivity testing results were known, 97/114 (85\%) of isolates were fully sensitive. An underlying condition associated with increased risk of invasive pneumococcal disease was documented in 14/120 $(12 \%)$ cases. The average highest recorded temperature within the first 12 hours was $39.0^{\circ} \mathrm{C}$ (range $36.2-40.6^{\circ} \mathrm{C}$ ). In $87 / 120(73 \%)$ cases, one or more neurological events were documented during admission, most commonly seizures in the first 48 hours $(36 \%, 43 / 120)$. Otitis media was documented in $12.5 \%(15 / 120)$.

\section{Treatment}

A total of $28 / 120$ cases (23\%) were recorded as receiving treatment with oral antibiotics prior to arriving in hospital, but testing for presence of antimicrobial substances in urine or CSF was not available. The most common parenteral antibiotic administered in hospital was cefotaxime (99/120), usually in combination with penicillin. All cases were treated with at least one antibiotic to which the isolated organism was sensitive. The median time from admission to administration of parenteral antibiotics was 4 hours (range 0-50 hours), with an average duration of 11.8 days (range $1-45$ days). In 20 cases, antibiotics were administered $>6$ hours after admission, and in 14 cases, $>12$ hours. Parenteral corticosteroids were used in 58/120 (48\%) cases, with timing of the first corticosteroid dose known in 57. The median time from admission to administration of corticosteroids was 4 hours (mean 13 hours, range $0-123$ hours); in 31/57 (54\%) cases, corticosteroids were administered after parenteral antibiotics. Figure 1 shows the timing of antibiotic and corticosteroid use. Most cases (64\%) treated with corticosteroids received at least four doses, consistent with at least two doses daily for two days, but 9 (16\%) received only one dose.

Table 2 Logistic regression models for predictors of death

\begin{tabular}{lcll}
\hline Variable & Odds ratio & $95 \% \mathbf{C l}$ & p value \\
\hline Female sex & 4.2 & 0.77 to 23.0 & 0.09 \\
1st presentation to hospital & 1.1 & 0.23 to 5.6 & 0.89 \\
Otitis media & 21.7 & 2.3 to 209 & 0.008 \\
Antibiotics prior to admission & 0.078 & 0.005 to 1.0 & 0.05 \\
Corticosteroids & 0.16 & 0.025 to 1.0 & 0.05 \\
Teaching hospital & 1.9 & 0.38 to 9.4 & 0.43 \\
Delayed hospitalisation & 0.60 & 0.09 to 4.0 & 0.60 \\
Lumbar puncture not done & 20.0 & 3.1 to 130.0 & 0.002 \\
Admission to intensive care & 9.9 & 1.7 to 56.6 & 0.01 \\
\hline
\end{tabular}


A total of 45 cases $(37.5 \%)$ were admitted to an intensive care unit (ICU), of whom 64\% (29/45) required intubation. The mean length of stay in ICU was 2 days (range 1-18 days).

\section{Survey data}

There were 30/105 survivors where, despite our best efforts, no survey data were obtained, but all cases with recorded morbidity had completed survey data. In all cases, morbidity detected by the survey, but not documented in hospital records consisted of mild hearing loss, and no additional cases of severe morbidity were found. Therefore, any undetected morbidity in the 30 cases not surveyed is likely to have been mild hearing loss.

\section{Outcomes}

About half the cases $(55 \%, 66 / 120)$ survived with no recorded sequelae. There were 15 deaths (13\% case fatality), three $(20 \%)$ within 24 hours of admission. Survey data on functional status after hospital discharge were obtained for $75 / 105$ survivors $(71 \%)$. Only one of the 30 cases with no survey data available (3\%) had been assessed as having any neurological abnormality at discharge.

Severe neurological impairment was recorded in 23/105 survivors $(22 \%)$, and mild to moderate neurological impairment (including hearing loss) in a further 16/105 (15\%). Hearing tests were recorded in only 52/105 survivors (50\%), of whom $27(52 \%)$ had sensorineural deafness. The level of hearing impairment was classified as severe in 17, but only 3/17 had hearing impairment as the sole neurological deficit.

\section{Univariate analysis}

Table 1 shows the results of univariate analysis. Significant diagnostic and prognostic predictors of outcome were not having a lumbar puncture done, intensive care admission, intubation, any neurological abnormality, seizures within 48 hours, and higher temperature. The only significant therapeutic factor was administration of corticosteroids with or before antibiotics. Administration of corticosteroids after antibiotics was not associated with any benefit (table 1). Delayed hospitalisation, antibiotic resistance (data not shown), and hours to antibiotic administration after admission were not significant predictors of outcome in univariate analysis.

Table 2 shows the results of multivariate modelling for predictors of death. Documented otitis media $(p=0.008)$, not having a lumbar puncture done $(p=0.002)$, and admission to intensive care $(p=0.01)$ were independently associated with a significantly increased risk of death. Use of antibiotics prior to admission $(p=0.05)$ and early parenteral corticosteroids $(p=0.05)$ tended to lower the risk of death, but did not reach statistical significance. Delayed hospitalisation was not associated with death.

Table 3 shows the results of multivariate modelling for predictors of the combined variable of any severe adverse outcome including death or severe morbidity. Intubation was the strongest predictor of severe adverse outcome. Early parenteral corticosteroids (administered before or with antibiotics) and first medical presentation to a hospital emergency department rather than a general practitioner, were each independently associated with significant protection against a severe adverse outcome.

When analysis was restricted to survivors only, the findings altered. First, predictors of severe hearing loss in survivors were examined in a logistic regression model (data not shown). Only the presence of any neurological abnormality during the hospital episode was significantly associated with severe hearing loss; corticosteroid use was not significantly protective (OR $0.49,95 \%$ CI 0.15 to 1.7 ). In a second model examining predictors of severe disability in survivors, delayed hospitalisation, female sex, and admission to intensive care independently predicted morbidity (table 4). Early corticosteroid use remained significantly protective after adjustment for these other variables. In contrast, the time to antibiotic use after admission (either within 4, 6, or 12 hours of admission versus later) was not significantly associated with morbidity in survivors, either in univariate analysis, or any of the models tested above. Antibiotic variables were also not associated with outcome, examined either as the nature of the antibiotic(s) used or sensitivity to penicillin.

To further elucidate patterns of steroid use, we examined factors predicting treatment with corticosteroids. In univariate analysis, gender was the only significant association with receipt of corticosteroids (OR 0.47 for males, $\mathrm{p}<0.05$ ). In a multivariate logistic regression model (not shown), gender remained significant, as did endotracheal intubation. Children who were intubated were significantly more likely to have received corticosteroids.

\section{DISCUSSION}

Pneumococcal meningitis resulted in mortality or permanent morbidity in $45 \%$ of children in our study. Total morbidity, particularly milder degrees of impairment, may have been greater, as we did not have complete data on follow up or performance of neuropsychological testing. ${ }^{14}$ We found that early parenteral administration of corticosteroids (before/ with initiation of antibiotics) significantly reduced severe adverse outcomes. Randomised controlled trials (RCTs) have shown a benefit of steroids in all-cause bacterial meningitis, predominantly Hib meningitis, ${ }^{15-17}$ strengthened by the results of meta-analysis. ${ }^{7}$ Another RCT of dexamethasone use, restricted to pneumococcal meningitis, found that there was no significant difference between treatment and placebo in rates of death and morbidity, but at three months after discharge, there was a significantly lower rate of hearing loss in the treatment group. ${ }^{18}$ A placebo controlled RCT in Malawi, in a setting of poor access to hospital care and sub-optimal antibiotic therapy, showed no benefit from corticosteroids. ${ }^{19}$ However, the results of RCTs may not readily translate to clinical practice, particularly with respect to early commencement of steroids.

\begin{tabular}{|c|c|c|c|}
\hline Variable & Odds ratio & $95 \% \mathrm{Cl}$ & $\mathrm{p}$ value \\
\hline 1 st presentation to hospital & 0.333 & 0.11 to 0.99 & 0.047 \\
\hline Otitis media & 3.9 & 0.97 to 15.6 & 0.054 \\
\hline Delayed hospitalisation & 0.42 & 0.12 to 1.5 & 0.17 \\
\hline Lumbar puncture not done & 2.5 & 0.59 to 11.1 & 0.21 \\
\hline Early corticosteroids & 0.21 & 0.05 to 0.77 & 0.020 \\
\hline Intubated & 6.7 & 2.2 to 20.2 & $<0.001$ \\
\hline Antibiotics prior to admission & 0.64 & 0.17 to 2.4 & 0.50 \\
\hline
\end{tabular}


Table 4 Logistic regression model for predictors of any morbidity in survivors*

\begin{tabular}{llll}
\hline Variable & Odds ratio & $95 \% \mathrm{Cl}$ & p value \\
\hline Female sex & 3.8 & 1.4 to 10.5 & 0.0096 \\
Delayed hospitalisation & 3.4 & 1.03 to 11.4 & 0.044 \\
lst presentation to hospital & 0.52 & 0.19 to 1.5 & 0.22 \\
Lumbar puncture not done & 2.7 & 0.46 to 15.8 & 0.27 \\
Antibiotics prior to admission & 0.53 & 0.16 to 1.8 & 0.31 \\
Admission to intensive care & 4.2 & 1.5 to 12.0 & 0.008 \\
Early parenteral corticosteroids & 0.15 & 0.04 to 0.50 & 0.002 \\
\hline *Cases without follow up data were excluded from analysis. & & \\
\hline
\end{tabular}

In Canada, a trend to decreasing use of corticosteroids was noted between 1991 and 1999, perhaps reflecting conflicting evidence. ${ }^{20}$ Unless clear protocols are in place, the commencement of steroids before or with antibiotics may be difficult to implement in emergency situations, as illustrated by our data (fig 1). Our data show that in a representative developed country population with good access to services, after controlling for other prognostic variables, early corticosteroid therapy is associated with improved outcome. This experience is an important addition to the findings from clinical trials of dexamethasone in pneumococcal meningitis in industrialised countries, ${ }^{21}$ as it shows that adjunctive steroid therapy is beneficial in a "real world" situation. In addition, the prospect of clinical trials in children, already limited by small case numbers, will be further reduced when the use of the conjugate pneumococcal vaccines is widespread. ${ }^{22}$

Two previous studies examined the impact of dexamethasone in childhood bacterial meningitis in clinical practice, one finding no significant benefit ${ }^{23}$ and the other a reduction in admissions to intensive care and in prolonged fevers. ${ }^{24}$ However, neither of these studies used multivariate analysis to adjust for confounding factors. In contrast to randomised trials, ${ }^{78}$ we did not find steroids gave significant protection against hearing loss in survivors, although the point estimate was in the direction of benefit. However, we only examined severe sensorineural hearing loss as an outcome, because only half the children received audiological testing. Thus, although the outcome of severe hearing loss was less likely to be affected by misclassification bias, restricted numbers limited the capacity to detect an effect.

In two studies no difference in outcome was found between cases of meningitis diagnosed early and late. ${ }^{25} 26$ The main contribution to outcome was postulated to be the severity of disease, with slowly evolving cases more likely to be diagnosed late. ${ }^{25}$ We found that delayed hospital admission did not predict the combined variable of death or severe neurological sequelae. However, when deaths were

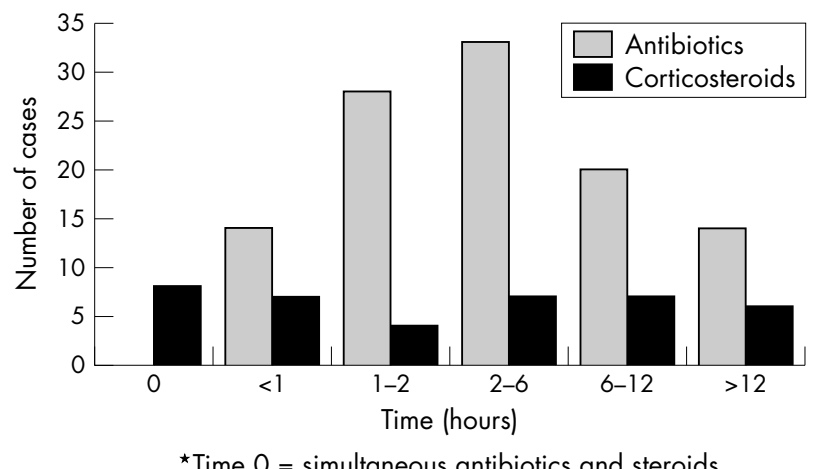

Figure 1 Time from hospital presentation to initiation of parenteral antibiotics and time to corticosteroid administration* in cases receiving parenteral antibiotics before corticosteroids. excluded, delayed hospitalisation significantly predicted morbidity in survivors. These data are limited by the lack of availability of supplementary survey data for 30 cases. However, these data add to those previously available on delayed diagnosis. It is plausible that delayed diagnosis has little impact on fulminant cases of meningitis, where death may not be averted even by early treatment. ${ }^{3627}$ However, in the remainder of cases, delay may be a determinant of outcome.

Clinical and prognostic predictors of outcome included temperature (both high and low), seizures, neurological signs, and whether or not a lumbar puncture was performed. The latter was significant, even when adjusted for severity of disease, in predicting death. This confirms the findings of the previous descriptive analysis of data from this population, ${ }^{8}$ and is likely to be due to an association between clinician assessment of contraindications to LP and a range of factors predicting an adverse outcome.

High and low temperature predicted death, but not other adverse outcomes. Presumably, extremes of temperature correlate with very severe disease leading to death, but not with less fulminant forms of disease. Similarly, seizures, neurological abnormalities, and admission to ICU were markers of disease severity, with intubation being the strongest marker, as found in previous studies.

Two factors not previously described as associated with adverse outcome were gender and a recorded diagnosis of otitis media. Interestingly, although males were overrepresented in the study population, female gender predicted adverse outcomes. This effect was seen even after adjusting for the gender discrepancy in receipt of corticosteroids. Whether otitis media is a genuine marker of more fulminant disease, such as high level bacteraemia associated with multifocal disease, or is itself associated with adverse outcomes is unclear.

Limitations of this study included some clinical data only being available from medical records due to incomplete physician follow up. Severe outcomes are likely to have been present at time of discharge from hospital and have been documented, but lesser degrees of morbidity may not have been detected in hospital or uncovered subsequently. Therefore, the lack of survey data for 30/105 survivors might result in an underestimate of mild disability. In particular, the low rate of testing for hearing could potentially bias the results towards underestimating the prevalence of less severe hearing loss. A major strength of this study was that the cases of pneumococcal meningitis described are likely to be representative of a diverse urban population, rather than patients of selected hospitals, as we used population based laboratory surveillance cross-checked with the hospital discharge coding data.

Together with other evidence, the findings of this study with respect to the benefits of early diagnosis and corticosteroid treatment have important prognostic, therapeutic and medico-legal implications in developed countries. Delayed diagnosis predicts morbidity in survivors, highlighting the 
importance of early recognition and treatment of the signs of meningitis. Our study shows a benefit of early corticosteroids, and a possible benefit of antibiotics administered before hospitalisation. Although not applicable in settings with delayed presentation to hospital and sub-optimal antibiotic choice such as Malawi, ${ }^{19}$ these data add to the previous evidence from meta-analysis of childhood trials ${ }^{7}$ and the recent randomised controlled trial in adults ${ }^{21}$ that adjunctive steroid therapy is beneficial in developed country settings. As severity of disease did not predict receipt of corticosteroids, the variation in clinical practice and evidence of rapidly declining steroid use in developed countries with available data, ${ }^{20}$ suggest the need for protocols to implement adjunctive corticosteroid use in childhood bacterial meningitis in emergency practice.

\section{Authors' affiliations}

P B Mclntyre, C R Maclntyre, R Gilmour, H Wang, National Centre for Immunisation Research and Surveillance of Vaccine Preventable Diseases, The Children's Hospital at Westmead and University of Sydney, NSW, Australia

Competing interests: none declared

\section{REFERENCES}

1 Short WR, Tunkel AR. Changing epidemiology of bacterial meningitis in the United States. Current Infectious Disease Reports 2000;2:327-31.

2 Mclntyre P, Gidding HF, Gilmour R, et al. Vaccine preventable diseases and vaccination coverage in Australia, 1999-2000. Comm Dis Intell 2002;(suppl May).

3 Grimwood K, Nolan TM, Bond L, et al. Risk factors for adverse outcomes of bacterial meningitis. J Paediatr Child Health 1996;32:457-62.

4 Neuman HB, Wald ER. Bacterial meningitis in childhood at the Children's Hospital of Pittsburgh: 1988-1998. Clin Pediatr 2001;40:595-600.

5 Kaplan SL. Management of pneumococcal meningitis. Pediatr Infect Dis J 2002;21:589-91.

6 Radetsky M. Duration of symptoms and outcome in bacterial meningitis: an analysis of causation and the implications of a delay in diagnosis. Pediatr Infect Dis J 1992;11:694-701.

7 Mclntyre PB, Berkey CS, King SM, et al. Dexamethasone as adjunctive therapy in bacterial meningitis. A meta-analysis of randomized clinical trials since 1988. JAMA 1997;278:925-31.

8 McMaster P, Mclntyre P, Gilmour R, et al. The emergence of resistant pneumococcal meningitis - implications for empiric therapy. Arch Dis Child 2002;87:207-11
9 National Coding Centre. ICD-9-CM, The official NCC Australian version. Sydney: Faculty of Health Sciences, University of Sydney, 1995.

10 Liddle JL, Mclntyre PB, Davis CW. Incidence of invasive pneumococcal disease in Sydney children, 1991-96. J Paediatr Child Health 1999:35:67-70.

11 The Australian immunisation handbook, 8th edn. Canberra: Australian Government Publishing Service, 2003.

12 Dean AG, Dean JA, Coulombier D, et al. Epi Info 6. Atlanta, GA: Centers for Disease Control, 1999.

13 Statistics and Epidemiology Research Corporation. EGRET for Windows. Seattle, WA: Cytel Software Corporation, 1999.

14 Grimwood K, Anderson P, Anderson V, et al. Twelve year outcomes following bacterial meningitis: further evidence for persisting effects. Arch Dis Child 2000;83:111-16.

15 Lebel MH, Freij BJ, Syrogiannopoulos GA, et al. Dexamethasone therapy for bacterial meningitis. Results of two double-blind, placebo-controlled trials. N Engl J Med 1988:319:964-71.

16 Odio CM, Faingezicht I, Paris $M$, et al. The beneficial effects of early dexamethasone administration in infants and children with bacterial meningitis. N Engl J Med 1991;324:1525-31.

17 Schaad UB, Lips U, Gnehm HE, et al. Dexamethasone therapy for bacterial meningitis in children. Swiss Meningitis Study Group. Lancet 1993;342:457-61.

18 Kanra GY, Ozen H, Secmeer G, et al. Beneficial effects of dexamethasone in children with pneumococcal meningitis. Pediatr Infect Dis J 1995;14:490-4.

19 Molyneux EM, Walsh AL, Forsyth $\mathrm{H}$, et al. Dexamethasone treatment in childhood bacterial meningitis in Malawi: a randomised controlled trial. Lancet 2002;360:211-18.

20 Kellner JD, Scheifele DW, Halperin SA, et al. Outcome of penicillinnonsusceptible Streptococcus pneumoniae meningitis: a nested case-control study. Pediatr Infect Dis J 2002;21:903-10.

21 de Gans J, van de Beek D. European Dexamethasone in Adulthood Bacterial Meningitis Study I. Dexamethasone in adults with bacterial meningitis. N Engl J Med 2002:347:1549-56.

22 Black S, Shinefield H, Fireman B, et al. Efficacy, safety and immunogenicity of heptavalent pneumococcal conjugate vaccine in children. Northern California Kaiser Permanente Vaccine Study Center Group. Pediatr Infect Dis J 2000; 19:187-95.

23 Arditi M, Mason EO Jr, Bradley JS, et al. Three-year multicenter surveillance of pneumococcal meningitis in children: clinical characteristics, and outcome related to penicillin susceptibility and dexamethasone use. Pediatrics 1998; 102:1087-97.

24 Buckingham SC, McCullers JA, Lujan-Zilbermann J, et al. Pneumococcal meningitis in children: relationship of antibiotic resistance to clinical characteristics and outcomes. Pediatr Infect Dis J 2001;20:837-43.

25 Kallio MJ, Kilpi T, Anttila M, et al. The effect of a recent previous visit to a physician on outcome after childhood bacterial meningitis. JAMA 1994;272:787-91.

26 Kilpi T, Anttila M, Kallio MJ, et al. Length of prediagnostic history related to the course and sequelae of childhood bacterial meningitis. Pediatr Infect Dis $J$ 1993; 12:184-8.

27 Kilpi T, Anttila M, Kallio MJ, et al. Severity of childhood bacterial meningitis and duration of illness before diagnosis. Lancet 1991;338:406-9. 